\title{
Doum Palm Meyve Kabuklarından Aktif Karbon Üretimi ve Karakterizasyonu
}

\author{
Özkan Açış11 ${ }^{*}$ \\ ${ }^{1}$ Ataturk University, Faculty of Earth Sciences, Department of Petroleum and Natural Gas Engineering, 25400, Oltu, Erzurum, Turkey, (ORCID:
} 0000-0002-4465-0916)

(İlk Geliş Tarihi 10 Haziran 2019 ve Kabul Tarihi 8 Temmuz 2019)

(DOI: $10.31590 /$ ejosat.574830)

\begin{abstract}
ATIF/REFERENCE: Açışl1, Ö. (2019). Doum Palm Meyve Kabuklarından Aktif Karbon Üretimi ve Karakterizasyonu. Avrupa Bilim ve Teknoloji Dergisi, (16), 544-551.

$\ddot{O} \mathbf{z}$

Çok gelişmiş bir iç yüzey alanına ve gözenekli yapıya sahip olan aktif karbon, organik ve inorganik maddeleri adsorplaması kapasitesi nedeniyle endüstrinin geniş bir alanında kullanılmaktadır. Bu çalışmada, Doum Palm (DP) meyve kabukları, 10 saat $\mathrm{ZnCl}_{2}$ ile aktive edildi ve aktive karbon elde etmek için 2 saat boyunca $900^{\circ} \mathrm{C}^{\prime} \mathrm{de}$ karbonizasyona maruz birakıldı. Aktif karbonun karakter analizi Xışııı difraksiyonu (XRD), taramalı elektron mikroskobu (SEM), enerji dağıtıcı X-1şını spektroskopisi (EDX), Fourier dönüşümü kızılötesi spektroskopisi (FTIR), Brunauer-Emmett-Teller (BET) ve Termal Gravimetrik Analiz (TGA) ile incelenmiştir. Çalışmada, aktif karbonun yüzey alanı ham numune için $84.629 \mathrm{~m}^{2} / \mathrm{g}$ ve aktif karbon için $433.192 \mathrm{~m}^{2} / \mathrm{g}$ olarak belirlenmiştir. Aktive edilmiş numunelerin gözenekliliğindeki artış, gözenek boyut dağılımından ve SEM görüntülerinden açıkça anlaşılmaktadır. Termal gravimetrik analiz sonuçları, ham numunenin bozulmasının iki aşamada gerçekleştiğini göstermektedir. Ayrıca, EDX analizi sonucunda aktif karbonun yapısındaki çinko elementi, aktivasyon işleminin başarıyla gerçekleştirildiğini göstermektedir.
\end{abstract}

\section{Characterization and Production of Activated Carbon from Doum Palm Fruit Shell}

\begin{abstract}
Activated carbon has a highly developed internal surface area and porosity is used in a wide industry area due to its adsorption capacity of organic and inorganic substances. In this study, doum palm fruit shells were activated with $\mathrm{ZnCl}_{2}$ for 10 hours and then exposed to carbonization at $900^{\circ} \mathrm{C}$ for 2 hours to obtain activated carbon. The character analysis of activated carbon was investigated by X-ray diffraction (XRD), scanning electron microscopy (SEM), energy dispersive X-ray spectroscopy (EDX), Fourier transform infrared spectroscopy (FTIR), Brunauer-Emmett-Teller (BET) and thermal gravimetric analysis (TGA). In the study, the surface area of activated carbon was determined as $84.629 \mathrm{~m}^{2} / \mathrm{g}$ for raw sample and $433.192 \mathrm{~m}^{2} / \mathrm{g}$ for activated carbon. The increase in the porosity of the activated samples is clearly apparent from the pore size distribution and SEM images. The thermal gravimetric analysis result showed that the degradation of the raw sample took place in two stages. Moreover, in the EDX analysis, the zinc element in the structure of the activated carbon indicates that the activation process was carried out successfully.
\end{abstract}

Keywords: Activated Carbon, Doum Palm Fruit, Porosity.

\footnotetext{
* Sorumlu Yazar: Atatürk Üniversitesi, Oltu Yer Bilimleri Fakültesi, Petrol ve Doğal Gaz Mühendisliği Bölümü, Oltu, Erzurum, Türkiye, ORCID: : 0000-0002-4465-0916,ozkan.acisli@atauni.edu.tr
} 


\section{Giriş}

Aktif karbon endüstride; gazların koku ve kirliliklerinin giderilmesinde, depolanmasında, gıda sanayinde, atık su arıtımında, sağlık sektöründe, metal ve savunma sanayisi gibi birçok alanda kullanılmaktadır (Saygılı, 2017). Aktif karbon karbon temelli kaynaklardan, \%70-90 aralığında karbon içerikli malzemelerin aktivasyon sürecinin son ürünüdür. Aktive edilmiş bir karbon, genişletilmiş parçacıklar arası yüzey alanı sergileyen yüksek derecede gözeneklilik içeren çok çeşitli amorf bazlı malzemeler içerir (Danish, Hashim, Ibrahim, \& Sulaiman, 2013). Aktif karbonun yüzey ve yapısal özelliklerini, seçilen hammadde ve onun aktive edilmesi sırasında uygulanan üretim metotları belirler (Sayg1l1, 2017).

Aktif karbonun aktivasyon işlemi genel olarak fiziksel aktivasyon işlemi ve kimyasal aktivasyon işlemi ile yapılır. Fakat nadir de olsa bu iki yöntemin birlikte kullanılması ile de hazırlanabilmektedir (Danish et al., 2013). Fiziksel aktivasyon işlemi karbonizasyon aşaması ve aktivasyon aşaması olarak iki basamakta sağlanmaktadır. Karbonizasyon işleminde hammadde inert gaz altında $600-800{ }^{\circ} \mathrm{C}$ aralığında karbonize edilmekte ve daha sonra su buharı, azot veya karbon dioksit kullanılarak aktivasyon sağlanmaktadır. Kimyasal aktivasyon işleminde ise, hammaddenin sülfürik asit (Hameed, Ahmad, \& Aziz, 2007), fosforik asit (Solum, Pugmire, Jagtoyen, \& Derbyshire, 1995), potasyum hidroksit (Jagtoyen \& Derbyshire, 1998), çinko klorür (Yorgun, Vural, \& Demiral, 2009) veya kalsiyum oksit (Danish et al., 2011) gibi kimyasal aktivatörlerle etkileştirilmesi esasına dayanmaktadır. Kimyasal aktivasyon işlemi; düşük sıcaklıklarda gerçekleştirilebiliyor olması ve ayrıca toplam verimin yüksek olması sebebiyle fiziksel aktivasyon işlemine göre daha üstün kılınmaktadır (Sahu, Acharya, \& Meikap, 2010). Kullanılan kimyasal aktivatörler arasında $\mathrm{ZnCl}_{2}$ en yaygın kullanılanıdır. Karbonizasyon işleminden önce, kullanılan hammadenin $\mathrm{ZnCl}_{2}$ ile muamele edilmesi, karbonizasyon esnasında nem giderimine (dehidrasyon), maddenin selilozik yapısının bozulmasına ve gözenekliliğinin düzenlenmesine neden olmaktadır. Karbonizasyon işleminden sonra, maddenin karbon iskeletinde çarlaşma ve aromatizasyonuna neden olarak, gözenekli yapının ortaya çıkmasını sağlayacaktır (Olivares-Marin, Fernandez-Gonzalez, Macias-Garcia, \& Gomez-Serrano, 2006). Aktif karbonda kullanılacak maddenin, bol miktarda, ucuz ve erişilebilir olması en önemli etkendir. Uzun süredir, lignoselülozik malzemeleri içeren odun, meyve kabuğu ve çekirdekleri gibi malzemeler aktif karbon üretiminde kullanılmaktadır (Saygılı, 2017).

Bu çalışmada, Sudan'dan temin edilen Doum Palm meyve kabuklarından aktif karbon üretilmesi amaçlanmıştır. Şimdiye kadar bahse konu olan meyve kabuklarından aktif karbon üretiminin yapıldığına ilişkin herhangi bir literatür verisine rastlanılmamıştır. Bu amaçla ögütülen meyve kabukları kimyasal aktivasyona $\left(\mathrm{ZnCl}_{2}\right)$ tabii tutulduktan sonra karbonizasyon işlemine geçilmiştir. Elde edilen aktif karbonun, yüzey özellikleri, gözenek dağılımı ve yapısal özellikleri XRD, FTIR, SEM, BET ve TGA gibi karakter analizleri ile aydınlatılmaya çalışılmıştır.

\section{Materyal ve Metot}

\subsection{Materyal ve kullanılan kimyasallar}

Hammadde olarak kullanılan Doum Palm (DP) meyve kabukları Sudan'dan temin edildi. Her türlü yüzey temizliği yapılan meyve kabukları çok sert olmaları münasebeti ile çeneli kırıcıda öğütülerek cm tanecik boyutuna getirildi. Daha sonra, destile su ile yıkanıp $70^{\circ} \mathrm{C}$ sıcaklıkta, 24 saat süreyle etüvde bekletilerek kurutuldu. Karbonizasyon ve aktivasyon işlemleri yüksek sıcaklıklı reaktör kullanılarak yapıldı. Karbonizasyon esnasında inert gazlardan azot gazı kullanıldı. Kimyasal aktivasyon işleminde kullanılan çinko klorür $\left(\mathrm{ZnCl}_{2}\right)$ analitik saflıkta olup, Sigma-Aldrich firmasından temin edildi.

\subsection{Aktif karbonun hazırlanması}

Doum Palm (DP) meyve kabuklarının kimyasal aktivasyonu için, $10 \mathrm{~g} \mathrm{ZnCl}$, $150 \mathrm{~mL}$ damıtılmış su içinde çözüldü ve daha sonra $10 \mathrm{~g}$ kurutulmuş DP meyve kabukları çinko klorit çözeltisi içine eklenerek; $85^{\circ} \mathrm{C}$ 'de yaklaşık 2 saat boyunca manyetik bir karıştırıcıda karıştırıldı. Karışımlar yaklaşık 24 saat $110{ }^{\circ} \mathrm{C}^{\prime}$ de etüvde kurutuldu. $\mathrm{ZnCl}_{2}$ ile muamele edilen numunelerin, karbonizasyon işlemi Protherm PZF 12/105/750 tüp firınında gerçekleştirildi. Numuneler $7 \mathrm{~cm}$ çapında ve $100 \mathrm{~cm}$ uzunluğunda cam reaktörün içine kondu. Tüp içerisinden $100 \mathrm{~mL} / \mathrm{dk}$ akış hızında inert gaz $\left(\mathrm{N}_{2}\right)$ geçirilerek, $10^{\circ} \mathrm{C} / \mathrm{dk}$ 1sıtma hızında, 1 saat $500{ }^{\circ} \mathrm{C}$ 'de 1 sıttılması sağlandı. Soğutma işlemi oda koşullarında ve azot gazı atmosferi altında yapıldı. Daha sonra numunelere, $0.2 \mathrm{M}, 500 \mathrm{ml} \mathrm{HCl}$ eklenerek 1 saat kaynamaya bırakıldı. Süzülen numunelerde $\mathrm{Cl}^{-}$iyonu kalmaması için, $\mathrm{AgNO}_{3}$ ile yıkama yapıldı. İşlem ortamda $\mathrm{Cl}^{-}$iyonları reaksiyon vermeyinceye kadar devam etti. Daha sonra $105^{\circ} \mathrm{C}$ 'de 24 saat etüvde kurutularak istenilen boyuta gelecek şekilde elenerek muhafaza edildi.

\subsection{Hammaddenin özellikleri}

Doum palm meyvesi kabukları meyvenin bir atığı olup, Afrika'da bolca görülen önemli bir biyokütle çeşididir. Bu çalışmada aktif karbon üretmek amacıyla Afrika-Sudan'dan getirilen doum palm meyve kabuklarının tane boyutu küçültülüp, elek analizi yapılarak 0.50-1.50 cm tane boyut aralığına sahip numuneler kullanılmıştır. Numunenin nem, uçucu madde, sabit karbon ve kül analizleri Protherm PLF fırını kullanılarak yapılmıştır. Elde edilen sonuçlar Tablo 1.'de verilmiştir. 
Tablo 1. Doum palm meyve kabuğunun ham ve kimyasal aktivasyon sonrası elde edilen numunelerin kısa analiz sonuçları

\begin{tabular}{|l|c|c|c|c|}
\hline \multicolumn{1}{|c|}{ Numune } & $\begin{array}{c}\text { Nem } \\
(\%)\end{array}$ & $\begin{array}{c}\text { Uçucu } \\
\text { Madde } \\
(\%)\end{array}$ & $\begin{array}{c}\text { Sabit } \\
\text { Karbon } \\
(\%)\end{array}$ & $\begin{array}{c}\text { Kül } \\
(\%)\end{array}$ \\
\hline Ham numune & 3.20 & 26.77 & 66.60 & 3.44 \\
\hline Aktive edilmiş numune & 5.50 & 41.65 & 50.24 & 2.62 \\
\hline
\end{tabular}

\subsection{Karakterizasyon çalışmaları}

Hazırlanan Doum Palm meyve kabuklarının karakterizasyonu çeşitli analizler ve ölçümler kullanılarak ayrıntılı olarak tanımlandı. $\mathrm{X}$ ışını kırınımı (XRD) analizleri, $\mathrm{Cu}-\mathrm{K} \alpha$ radyasyonu (40 kV, $30 \mathrm{~mA}, 1.54051 \AA$ ) bulunan bir PANalitik Empyrean cihazı (ABD) kullanılarak yapıldı. Aktif Karbonun ve karbonun yüzey fonksiyonel gruplarının nitel olarak belirlenmesi için FT-IR Spektrofotometrik analizleri Tensor 27, Bruker cihazı (Almanya) kullanılarak, 4000-400 $\mathrm{cm}^{-1}$ aralığında, potasyun bromür tekniği ile yapıldı. Karbonun ve Aktif karbonun yüzey fiziksel morfolojileri ve elementel bileşimleri EDX bağlantılı SEM cihazı (Zeiss Sigma 300, Almanya) kullanılarak incelendi. Elde edilen aktif karbonun gözenek boyut dağılımı, karakteristiği ve yüzey alanı $77 \mathrm{~K}$ 'deki azot $\left(\mathrm{N}_{2}\right)$ adsorpsiyondesorpsiyonu ile Micromeritics 3Flex cihazı kullanılarak belirlendi. Termal Gravmetrik özellikleri ise Netzsch STA 409 PC Luxx cihazı kullanarak belirlendi.

\section{Bulgular ve Tartışma}

\subsection{XRD Kristalografik analizi}

Aktif karbon üretiminde kimyasal aktivasyon ve karbonizasyon işlemi, maddenin moleküler, kristalin ve biyokütlesinde önemli değişikliklere neden olmaktadır. Bu nedenle değişen bu yapının, karakterize özelliklerini belirleme de XRD yaygın olarak kullanılan yöntemlerden biridir (Saygıll, 2017).

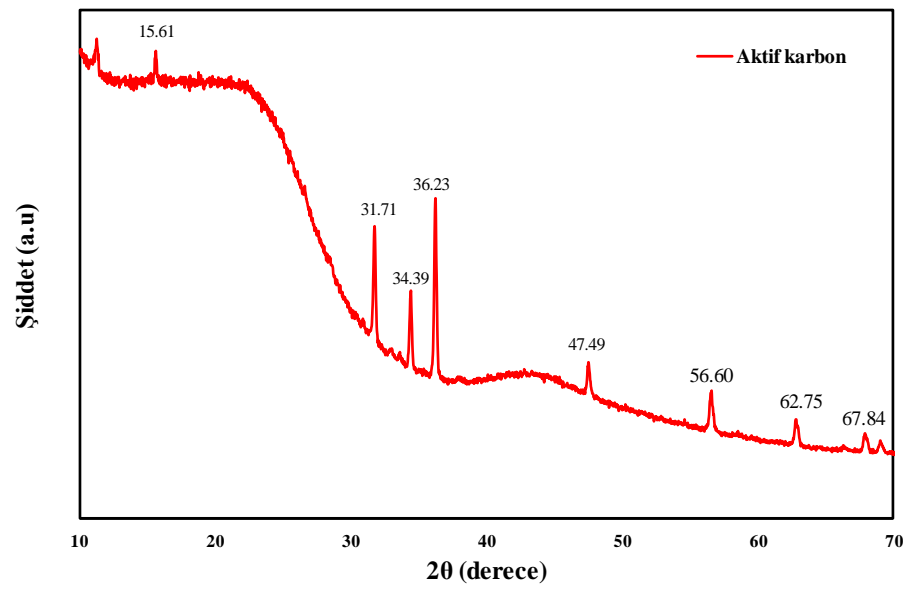

Şekil 1. Doum Palm (DP) ve Aktive edilmiş Doum Palm (DPAK)'un X-ray difraksiyon analizi

Yapılan analizde gözlemlenen, $2 \theta=31.71^{\circ}$ de gözlemlenen keskin pik, aktif karbonun defalarca yıkanmasına rağmen aktifleştirilmesi sırasında gözlemlenen ve $\mathrm{ZnO}$ ait olan piktir ve ayrıca bu pik amorf selüloz yapısının varlığını da işaret etmektedir (Saygıll, 2017; Wang et al., 2015). Ayrıca $2 \theta=15.61^{\circ}$ karakteristik piki maddenin selülozlozik yapı içerdiğine de işaret etmektedir (Zhang et al., 2015). Ayrıca, $2 \theta=34.39^{\circ}, 31.71^{\circ}, 36.17^{\circ}$ keskin pikleri aktif karbonun varlığını doğrulayan temel piklerdir (Kumar, Amarnath, Jabasingh, \& Sathish, 2016).

\subsection{FTIR Analizi}

Kimyasal aktivasyon yöntemi ile elde edilen aktif karbonda meydana gelen yapısal değişiklikleri belirlemek için FTIR analizleri gerçekleştirilmiştir. FTIR spektrumları, yüzeydeki fonksiyonel grupların dağılımlarının nitel analizinde kullanılan önemli bir yöntemdir (Saygıll, 2017). Sekil 6.'da ise kimyasal aktivasyon işlemi ile elde edilen aktif karbonun FTIR grafikleri görülmektedir. Bilindiği üzere odunsu yapıların FTIR bileşenleri başlıca; selilozik yapılarda bulunan fenolik ve polifenolik $\mathrm{OH}$ grupları, polisakkaritlerin $\mathrm{OH}$ grupları, karbonil ve aromatik yapıda bulunan $\mathrm{C}=\mathrm{C}$ grupları ve ayrıca ketonlardan ve alkil gruplarından (hemiselüloz, reçineler) oluşmaktadır (Tasmakıran, 2010; Viera et al., 2007). Bu grupları içeren odunsu yapıdaki maddelerin FTIR grafikleri incelendiğinde aşağıdaki bulgular elde edilmiştir. 


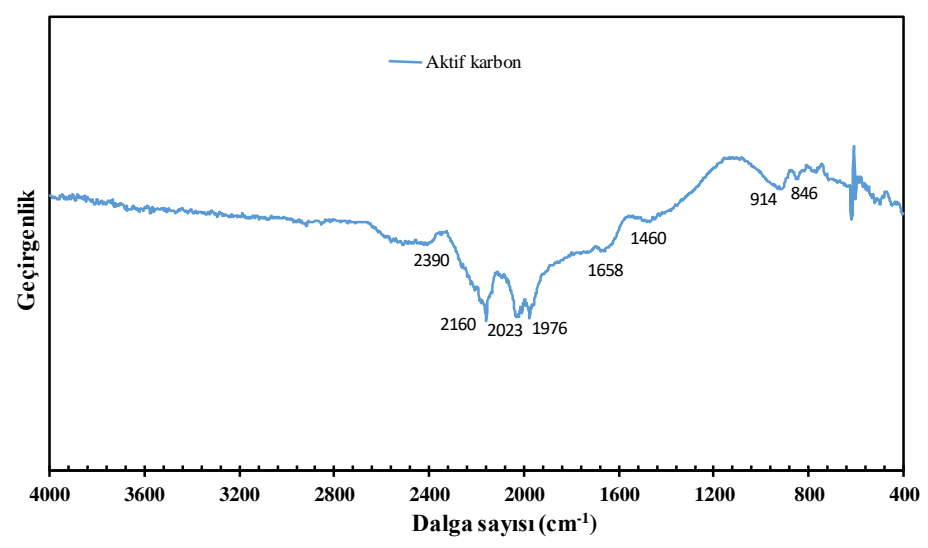

Şekil 2. Aktive edilmiş Doum Palm meyve kabuklarının yüzey fonksiyonel grup (FTIR) analizi

Spektrumda $875-750 \mathrm{~cm}^{-1}$ arasında gözlemlenen bantların aromatik yapıdaki $\mathrm{C}-\mathrm{H}$ bükülme titreşimlerinden kaynaklandığı söylenebilir (Zhang et al., 2015). Ayrıca, 800-1000 cm-1 bandı aralığında kalan $914 \mathrm{~cm}^{-1}$ piki, C-OH gerilmelerinden kaynaklanan piklerdir (İskeçeli, 2010). $1460 \mathrm{~cm}^{-1}$ arasında gözlemlenen band, $\mathrm{C}-\mathrm{O}$ germe titreşimlerine atfedilebilir (Zhang et al., 2015). 1658 $\mathrm{cm}^{-}$ 1 civarında gözlemlenen pik, pek çok araştırmacı tarafından tam olarak açıklanamamış olmakla birlikte karbonlu malzemelerdeki aromatik $\mathrm{C}=\mathrm{C}$ gerilimlerinin bir sonucu olduğu bildirilmiştir, aldehit, keton, ester ve karboksilik asitler bu tip bağ yapısına sahip organik gruplardır (Örkün, 2011). Diğer taraftan, $2390 \mathrm{~cm}^{-1}$ de görülen geniş band, aktik karbon- $\mathrm{ZnCl}_{2}$ çoklu bağ germe titreşimine atfedilebilir (Danish et al., 2013). 1900-2200 $\mathrm{cm}^{-1}$ aralığında görülen salınım pikleri metil selüloz pikleri ile uyum içindedir, benzer salınım pikleri Vierre, R ve arkadaşları tarafından yapılan şeker kamışından metil selüloz eldesi ile ilgili çalışmada, elde edilen FTIR pikleri ile uyum içindedir (Viera et al., 2007). Yapı metil klorür ile selülozun kimyasal reaksiyonu sonucu oluşabilir.

\subsection{Morfolojik analizlerinin değerlendirilmesi}

Taramalı elektron mikroskobu (SEM), incelenen malzemelerin yüzey morfolojilerinin ve yüzey fiziksel özelliklerinin belirlenmesinde kullanılan bir tekniktir. Numunenin kimyasal olarak aktifleştirilmiş ve aktifleştirilmemiş hallerinin karbonizasyon sonrası çekilen taramalı elektron mikroskobu görüntüleri aşağıda Şekil 3.’te verilmektedir. Ham numunenin SEM görüntüsüne bakıldığında, malzemenin dış yüzeyinin oldukça girinti ve çıkıntılara sahip pürüzlü bir yüzeyden oluştuğu görülmektedir. $\mathrm{ZnCl}_{2}$ ile yapılan kimyasal aktivasyon işlemi ve akabinde yapılan karbonizasyon işleminden sonra numunede bulunan uçucu bileşenlerin uzaklaştığ1 ve sonucunda çukurların oluştuğu görülmektedir. Burada kimyasal aktivasyon ve karbonizasyon işlemi süresince numunede gözeneklerin geliştiği ve yüzeyin heterojen bir yapıya kavuştuğu görülmektedir. Bu durum, ham yapının aktif karbona dönüştüğünün göstergesidir ve SEM görüntüleri ile belirgin bir şekilde görülmektedir (Saygılı, 2015)

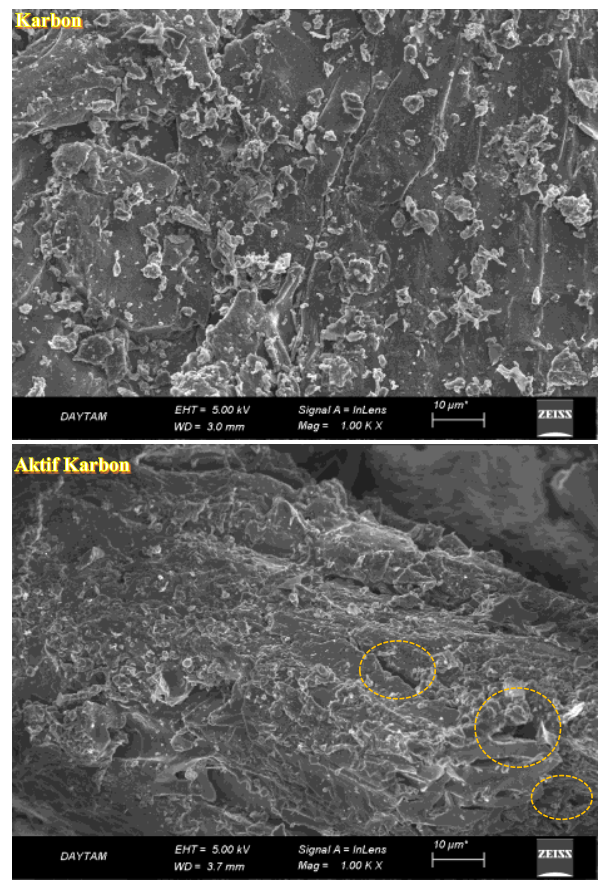

Şekil 3. Doum Palm (DP) ve aktive edilmiş Doum Palm (DPAK)'un taramalı elektron mikroskobu (SEM) analizi 
Gözeneklilikteki artış $\mathrm{N}_{2}$ adsorpsiyon-desorpsiyon izoterminden de belirgin bir şekilde görülmektedir. Elde edilen aktif karbonun yüksek yüzey alanına sahip olduğu ve gözenek hacminin, mikro ve mezo yapılı oldukça geniş bir gözenek boyut dağılımına sahip olduğu görülmüştür. Ayrıca hammaddede var olan farklı oksijen içerikli grupların kimyasal aktivasyon ve karbonizasyon işlemi boyunca karbonlu yapının, oksidatif bozunma sonucunda aromatizasyona uğradığı ve bu durumun aktif karbonda bazı karbonil gruplarının dekompoze olduğunu göstermiştir. Şekil 4'de EDX grafiklerine bakıldığında ZnCl'ün emdirilmesinden kaynaklı aktif karbonda Cl elemeti kütlece \% 4.61 oranında bulunurken bu durum kimyasal aktivasyona uğramayan doum palm meyve kabuklarında gözükmemektedir.
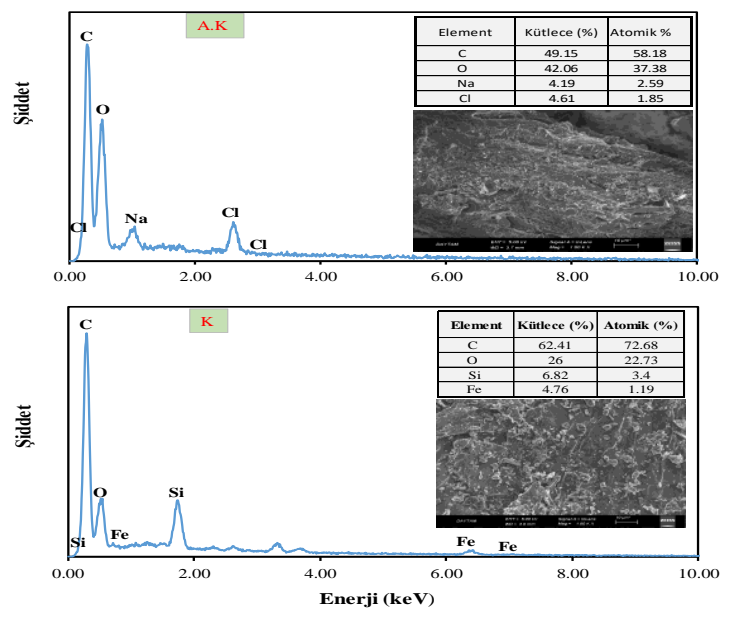

Şekil 4. Hammadde (DP) ve Aktif Karbonun (DPAK) EDX analizi

\subsection{Yüzey alanı ve gözenek boyut dağılım analizi}

Şekil 5, DP ve DPAK'dan hazırlanan aktif karbonun $\mathrm{N}_{2}$ adsorpsiyon-desorpsiyon izotermini ve Şekil 6'da DP ve DPAK'nın gözenek boyut dağılımını göstermektedir. Tablo 2 ise adsorpsiyon-desorpsiyon izotermlerinden belirlenen gözenek karakteristiklerini içermektedir.

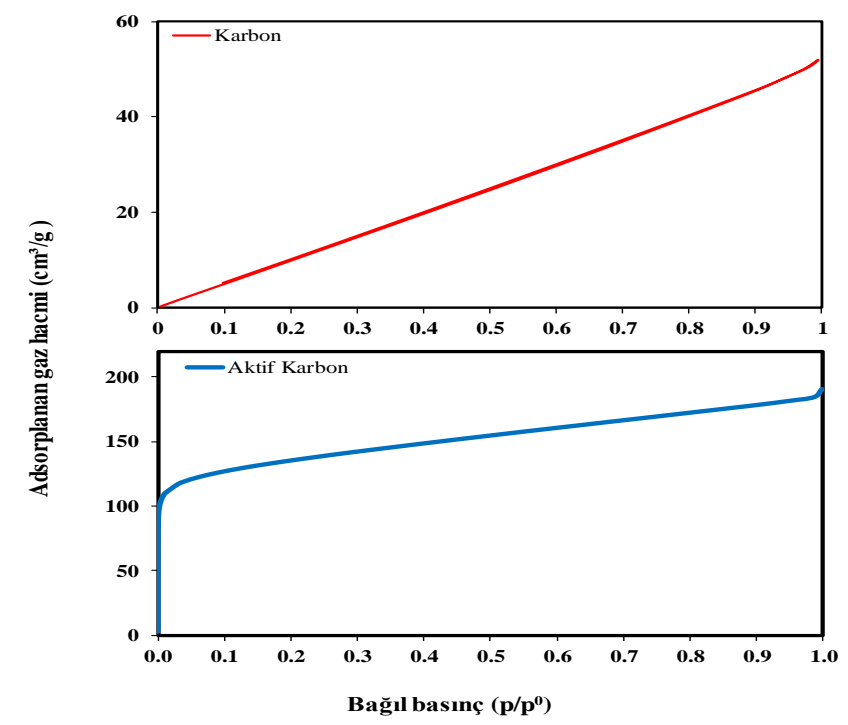

Şekil 5. Doum Palm meyve kabuklarından üretilen aktif karbonun azot adsorpsiyon-desorpsiyon izoterm grafiğgi

Şekil 5'den görülebileceği gibi aktive edilmiş karbonda (DPAK), düşük nispi basınçlarda, adsorpsiyon-desorpsiyon izotermlerinde hızlı bir artış gözlenir; bunu, daha yüksek nispi basınçlarda neredeyse yatay bir plato izleyerek devam etmektedir. Bu durum IUPAC'ın sınıflandırmasına göre tanımlanmış, Brunauer, Deming, Deming ve Teller (BDDT) izoterm sınıflandırmasından Tip I izoterm tipini göstermektedir (Yorgun et al., 2009). Tip I izotermi, mikro gözenekli yapıya sahip bir materyali temsil eder. Adsorpsiyondaki ana alım, Şekil 5'te gösterildiği gibi, ağırlıklı olarak dar gözenek büyüklüğü dağılımına sahip çok gözenekli malzemelerin oluşumunu gösteren düşük nispi basınçlarda meydana gelir (Yorgun et al., 2009). Grafik boyunca herhangi bir kılcal yoğunlaşanın olmadığı ve dolayısıyla herhangi bir histerezis ilmeğinin de oluşmadığı görüldü. Bu izoterm tipi karakteristik olarak oldukça fazla miktarda küçük gözeneklere sahip adsorbentlerde görülen bir durumdur (Örkün, 2011). 


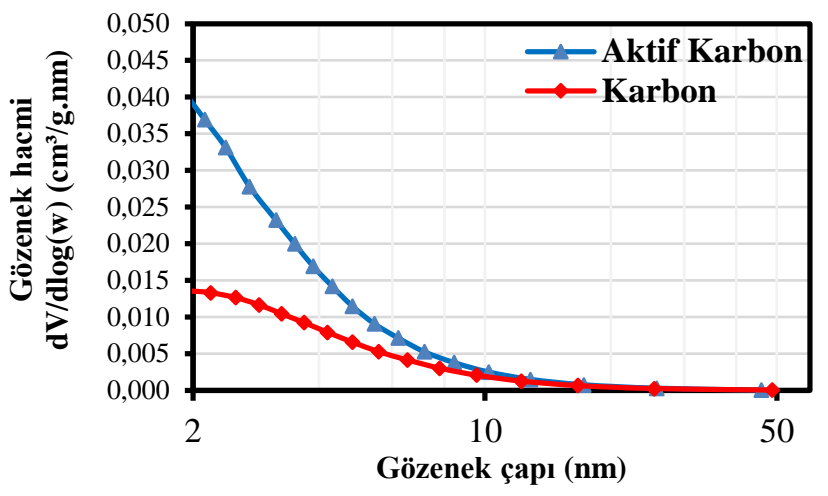

Şekil 6. Doum Palm meyve kabuklarından üretilen aktif karbonun gözenek boyut dağılımı

Şekil 6'da doum palm meyve kabuklarından hazırlanan aktif karbonun ve karbonun gözenek boyut dağılımını içeren grafik yer almaktadır. Adsorplayıcı gözenekleri, IUPAC'ın sınıflandırmasına göre; makro gözenek (çap > 50nm), mezo gözenek $(2<$ çap > 50nm) ve mikro gözenek (çap < 2nm) olarak üç gruba ayırmak mümkündür (Örkün, 2011).

Tablo 2. Doum palm meyve kabuklarından üretilen aktif karbonun gözenek karakteristik değerleri

\begin{tabular}{|l|c|c|}
\hline \multicolumn{1}{|c|}{ Değerler } & Karbon & Aktif Karbon \\
\hline BET yüzey alanı $\left(\mathrm{m}^{2} / \mathrm{g}\right)$ & 84.629 & 433.192 \\
\hline BJH toplam yüzey alanı $\left(\mathrm{m}^{2} / \mathrm{g}\right)$ & 63.782 & 139.202 \\
\hline Toplam por hacmi $\left(\mathrm{cm}^{3} / \mathrm{g}\right)$ & 0.072 & 0.131 \\
\hline Ortalama por çap1 $(\mathrm{nm})$ & 4.495 & 3.765 \\
\hline
\end{tabular}

Şekil 6'dan aktif karbonun gözenek boyut dağılım grafiği incelendiğinde, malzemenin gözenek dağılımının 2-50 nm değerleri arasında yer aldığı görülmüştür. Gözenek boyut dağılım eğrisinden, elde edilen malzemenin ortalama gözenek çapı (Dp) değerinin 3.76 $\mathrm{nm}$ olduğu belirlenmiş ve gerekli değerler Tablo 2'de verilmiştir. PDAK için belirlenen bu değer, gelişmiş mikro gözeneklere sahip olmasının yanı sıra içerisinde ağırlıklı olarak mezo gözenekli yapınında olduğu sonucunu teyit etmektedir (Saygıll, 2015). Gözenekler tipik olarak, bir kere adsorbe ile doldurulan ve daha fazla adsorpsiyon için neredeyse hiç ya da çok az dış yüzey bırakan, mikroporoz yapılardır (Leddy, 2012).

\subsection{Termal Gravmetrik Analiz}

Karbonizasyon sıcaklığı ve emdirme oranı, aktif karbon verimini etkileyen en önemli işlem parametreleri olarak kabul edilebilir (Açıkyıldız, Gürses, \& Karaca, 2014). Aktif karbon numunelerinin termal bozunma özelliklerini analiz etmek ve termal davranışları belirlemek için; termogravimetri analizi (TGA) Netzsch STA 409 PC Luxx cihazı kullanarak sıcaklığın bir fonksiyonu olarak hesaplandı. Ölçüm için, yaklaşı $5 \mathrm{mg}$ numune, bir mikrobalansın tavası üzerinde bir potaya yerleştirildi ve daha sonra, $20 \mathrm{~mL} / \mathrm{dak}$ hava akış hızında, $10 \mathrm{~K} / \mathrm{dak}$. Isıtma hızında, $22{ }^{\circ} \mathrm{C}$ ile $900{ }^{\circ} \mathrm{C}$ arasında 1 sıtıldı ve sürekli olarak tartıldı. Şekil 7 , Doum palm meyve kabuklarının termal ayrışması için hava atmosferinde $10 \mathrm{~K} / \mathrm{dk}$ 1sıtma oranlarında gerçekleştirilen TGA eğrisini göstermektedir.

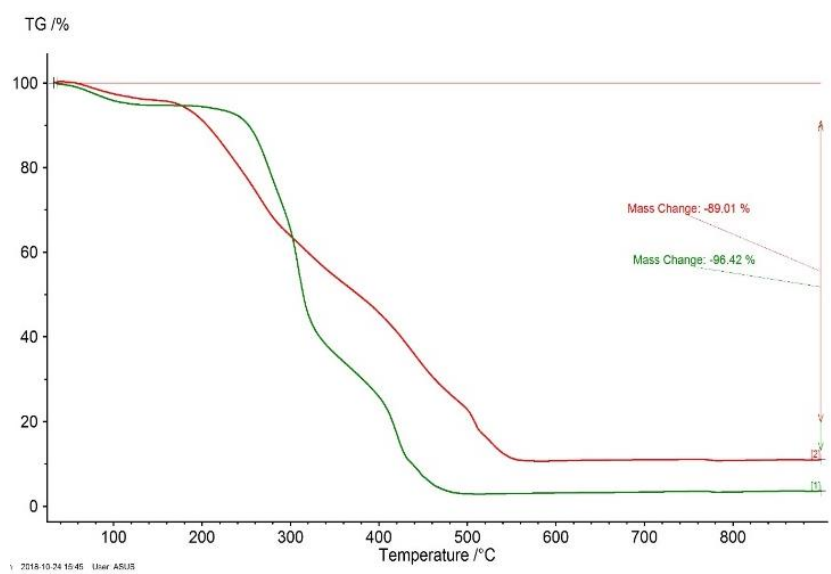

Şekil 7. Doum Palm meyve kabuklarının termal gravmetrik analizi 
Şekil 7'de TGA grafiğinde görüldüğü gibi, doum palm meyve kabukları için karbonizasyon sıcaklığının iki aşamalı bir bozunma davranışı gösterdiği görülmüştür. Ayrışma sıcaklıklarının, ısıtma oranındaki bir artışla arttığı görülmektedir. İlk aşamada (383 ila $523 \mathrm{~K}$ arasında), termal ayrışma, su ve hafif uçucu bileşiklerin kütle kaybına bağlanabilir. İkinci aşamada ise (533-873 K) hidrokarbon malzemenin ayrışmasını ve gazların ve yağ buharının evrimini içerir.

\section{Sonuç ve Öneriler}

$\mathrm{Bu}$ çalışmada doum palm meyve kabuklarının $\mathrm{ZnCl}_{2}$ ile kimyasal aktivasyonu sağlanmış ve elde edilen aktif karbonun yapısal, morfolojik ve gözenek özellikleri incelenmiştir.

$\checkmark$ XRD spektrumu elde edilen aktif karbonun grafitik tip karbon olduğunu,

$\checkmark \quad$ FT-IR spektrumu, doum palm meyve kabuklarında oksijen içerikli grupların, kimyasal aktivasyon ve karbonizasyon süresince karbonlu yapının aromatizasyona uğradığı ve bazı karbonil grupların bozunduğu,

$\checkmark \quad$ Elde edilen aktif karbonun, $\mathrm{N}_{2}$ adsorpsiyon-desorpsiyon izotermine bakınca yüzey alanının önemli ölçüde arttı̆̆ı, mikro ve mezo gözeneklere sahip boyut dağılımına sahip olduğu,

$\checkmark \quad$ SEM görüntüleri kimyasal aktivasyon ve karbonizasyon işlemlerinin etkisiyle doum palm meyve kabuklarının gözenekliliğinin gelişerek aktif karbona dönüştüğü, görülmüştür.

Bütün bunların sonucunda üretilen malzemenin aktif karbon olarak kullanılabileceğinin sonucunu çıkarmak mümkündür.

\section{Teşekkür}

XRD, FTIR, SEM, BET ve EDX analizlerimiz Atatürk Üniversitesi Doğu Anadolu Yüksek Teknoloji Merkezinde (DAYTAM); Termal Gravmetrik Analizi ve Karbonizasyon işlemini yapan Dr. Öğr. Üyesi Hatice Bayrakçeken'e ve Sudan'dan Doum palm meyvelerini getiren Arş. Gör. Faisal Mohamedgread'a çok teşekkür ederim.

\section{Kaynaklar}

Açıkyıldız, M., Gürses, A., \& Karaca, S. (2014). Preparation and characterization of activated carbon from plant wastes with chemical activation. Microporous and Mesoporous Materials, 198, 45-49. doi:https://doi.org/10.1016/j.micromeso.2014.07.018

Danish, M., Hashim, R., Ibrahim, M. N. M., Rafatullah, M., Sulaiman, O., Ahmad, T., . . Ahmad, A. (2011). Sorption of Copper(II) and Nickel(II) Ions from Aqueous Solutions Using Calcium Oxide Activated Date (Phoenix dactylifera) Stone Carbon: Equilibrium, Kinetic, and Thermodynamic Studies. Journal of Chemical and Engineering Data, 56(9), 3607-3619. doi:10.1021/je200460n

Danish, M., Hashim, R., Ibrahim, M. N. M., \& Sulaiman, O. (2013). Effect of acidic activating agents on surface area and surface functional groups of activated carbons produced from Acacia mangium wood. Journal of Analytical and Applied Pyrolysis, 104, 418-425. doi:10.1016/j.jaap.2013.06.003

Hameed, B. H., Ahmad, A. A., \& Aziz, N. (2007). Isotherms, kinetics and thermodynamics of acid dye adsorption on activated palm ash. Chemical Engineering Journal, 133(1-3), 195-203. doi:10.1016/j.cej.2007.01.032

İskeçeli, M. (2010). KESTANE KABUKLARINDAN SENTETĐK AKTĐF KARBON HAZIRLAMASI VE METĐLEN MAVĐSÐ GĐDERDMĐNDE KULLANILMASI.

Jagtoyen, M., \& Derbyshire, F. (1998). Activated carbons from yellow poplar and white oak by H3PO4 activation. Carbon, 36(7-8), 1085-1097. doi:Doi 10.1016/S0008-6223(98)00082-7

Kumar, J. A., Amarnath, D. J., Jabasingh, S. A., \& Sathish, S. (2016). Thermo-chemical sequestration of naphthalene using Borassus flabellifer Shell activated carbon: Effect of influencing parameters, isotherm and kinetic study. African Journal of Biotechnology, 15(48), 2703-2713.

Leddy, N. (2012). SURFACE AREA AND POROSITY. In. CMA Analytical Workshop.

Olivares-Marin, M., Fernandez-Gonzalez, C., Macias-Garcia, A., \& Gomez-Serrano, V. (2006). Preparation of activated carbon from cherry stones by chemical activation with ZnCl2. Applied Surface Science, 252(17), 5967-5971. doi:10.1016/j.apsusc.2005.11.008

Örkün, Y. (2011). FINDIK KABUĞUNDAN FIZIKSEL VE KIMYASAL AKTIVASYONLA AKTIF KARBON ÜRETIMİ VE KARAKTERIZASYONU. (YÜKSEK LISANS TEZI), İSTANBUL TEKNIK ÜNIVERSITESİ,

Sahu, J. N., Acharya, J., \& Meikap, B. C. (2010). Optimization of production conditions for activated carbons from Tamarind wood by zinc chloride using response surface methodology. Bioresource Technology, 101(6), 1974-1982. doi:10.1016/j.biortech.2009.10.031

Saygılı, H. (2015). Bazı Bitkisel Posalardan Nano Gözenekli Aktif Karbonlar Üretilmesi ve Bazı Adsorpsiyon Uygulamalarında Kullanilabilirliğinin İncelenmesi. Dicle

Saygıll, H. (2017). Yeni bir hammaddeden üretilmiş karbonlu malzemenin yapısal, morfolojik ve gözenek özellikleri üzerine çalışmalar. DÜMF Mühendislik Dergisi, 8(1), 245-252.

Solum, M. S., Pugmire, R. J., Jagtoyen, M., \& Derbyshire, F. (1995). Evolution of Carbon Structure in Chemically Activated Wood. Carbon, 33(9), 1247-1254. doi:Doi 10.1016/0008-6223(95)00067-N

Tasmakıran, A. F. (2010). Zirai Yan Ürünlerin Modifiye Edilerek Yeni Adsorbanların Hazırlanması ve Boyaların Adsorpsiyonu. 
Viera, R. G. P., Filho, G. R., de Assunção, R. M. N., S. Meireles, C. d., Vieira, J. G., \& de Oliveira, G. S. (2007). Synthesis and characterization of methylcellulose from sugar cane bagasse cellulose. Carbohydrate Polymers, 67(2), 182-189. doi:https://doi.org/10.1016/j.carbpol.2006.05.007

Wang, K., Zhao, N., Lei, S., Yan, R., Tian, X., Wang, J., . . Liu, L. J. E. A. (2015). Promising biomass-based activated carbons derived from willow catkins for high performance supercapacitors. 166, 1-11.

Yorgun, S., Vural, N., \& Demiral, H. (2009). Preparation of high-surface area activated carbons from Paulownia wood by $\mathrm{ZnCl2}$ activation. Microporous and Mesoporous Materials, 122(1-3), 189-194. doi:10.1016/j.micromeso.2009.02.032

Zhang, L., Wang, Q., Wang, B. B., Yang, G. H., Lucia, L. A., \& Chen, J. C. (2015). Hydrothermal Carbonization of Corncob Residues for Hydrochar Production. Energy \& Fuels, 29(2), 872-876. doi:10.1021/ef502462p 